\title{
6. GEOPHYSICAL PROPERTIES OF OCEANIC CRUST AT SITES 768 AND 770 ${ }^{1}$
}

\author{
Richard D. Jarrard ${ }^{2}$ and Cristina Broglia ${ }^{2}$
}

\begin{abstract}
Velocity, density, resistivity, and neutron-porosity logs were recorded in virtually the entire 222-m-thick section of basaltic back-arc crust drilled at Site 768 and through the 106-m section of MORB crust at Site 770. Our analysis of these logs and comparison with measurements on discrete cores permit determination of interlog relationships and evaluation of the reliability of each log.

Crustal porosity $(\phi)$ at the two sites is most accurately determinable from transit time $(\Delta t)$ and the inverse of velocity: $\varphi=0.0054 \cdot \Delta t-0.259$. Porosity is also closely related to resistivity $\left(R_{o}\right)$, according to the Archie equation: $R_{o}=R_{w} a \varphi^{-m}$ where $R_{\mathrm{w}}$ is resistivity of the formation fluid, and $a$ and $m$ are empirically determined "constants." Both logs and cores indicate that $a$ and $m$ range from 2 to 6.5 and 1.2 to 1.6 , respectively. Density values estimated from sonic porosity are broadly similar to, but more reliable than, density logs. Neutron-porosity logs yield values $10 \%-20 \%$ higher than actual porosities; this error is caused primarily by lack of proper tool eccentralization and secondarily by the presence of hydrous alteration minerals in the rocks.

These in-situ geophysical properties of oceanic crust $18 \mathrm{Ma}$ and $42 \mathrm{Ma}$ help to bridge the in-situ measurement gap between 6 $\mathrm{Ma}$ and $110 \mathrm{Ma}$ at other sites. Observed velocities, densities, and porosities are generally similar to predictions from crustal aging models. We infer that this correspondence is largely coincidental; observed properties here are related more to style of volcanism than to crustal aging, and crustal heterogeneity is so high that a $100-200-\mathrm{m}$-interval is not representative of larger scale geophysical properties.
\end{abstract}

\section{INTRODUCTION}

The standard model for the hydrologic evolution of oceanic crust is elegantly simple and accounts for many geophysical observations. According to the standard model, newly created oceanic crust is very hot, very porous, and very permeable, with porosity composed of interpillow voids, microcracks, vesicles, and fractures. Consequently, hydrothermal circulation is vigorous. Associated with this hydrothermal flux is mass flux into and out of the formation, resulting in black smokers on the seafloor and alteration of the upper $1 \mathrm{~km}$ or more of crust. Velocities and densities increase while porosity and permeability decrease and magnetic minerals oxidize.

Over the next several million years, hydrothermal circulation wanes, due to decrease in crustal heat, accumulation of a relatively low-permeability sediment cover, and decrease in crustal permeability caused by crustal alteration. All three of these factors undoubtedly play a role in decreasing hydrothermal circulation, but crustal alteration has received the most attention because only it can account for the age-dependence of upper crustal velocities. Based on sonobuoys, it has long been known that the uppermost crustal velocities (Layer 2A) increase with increasing crustal age from a velocity of about $3.2 \mathrm{~km} / \mathrm{s}$ for zero-age crust to about 4.4 $\mathrm{km} / \mathrm{s}$ for 30-Ma crust (Houtz and Ewing, 1976). Some confirmation of this pattern has been obtained from three holes drilled and logged by the Deep Sea Drilling Project (DSDP) and Ocean Drilling Program (ODP): Atlantic Hole 395A (6 Ma), Pacific Hole 504B (6 Ma), and Atlantic Hole 418A (110 Ma). In-situ data of intermediate age are virtually absent, and remote geophysical measurement tools such as sonobuoys, multichannel seismics, proton precession magnetometers, and heat-flow probes give only a generalized and somewhat ambiguous picture of crustal aging.

\footnotetext{
${ }^{1}$ Silver, E. A., Rangin, C., von Breymann, M. T., et al., 1991. Proc. ODP, Sci. Results, 124: College Station, TX (Ocean Drilling Program).

${ }^{2}$ Lamont-Doherty Geological Observatory, Columbia University, Palisades, NY 10964, U.S.A.
}

ODP Leg 124 cored $106 \mathrm{~m}$ of basaltic crust at Site 770 in the Celebes Sea and $222 \mathrm{~m}$ of basaltic crust at Site 768 in the Sulu Sea (Shipboard Scientific Party, 1990b and 1990c). Based on trace-element geochemistry and other data, the basalts at Site 770 are mid-ocean ridge basalts (MORB), formed in the middle Eocene and apparently later trapped as the Celebes Sea by microplate reorganization (Shipboard Scientific Party, 1990b). In contrast, the basalts at Site 768 formed by back-arc spreading in the early middle Miocene (Shipboard Scientific Party, 1990a). Complete suites of in-situ geophysical logs were obtained through both basalt intervals; these logs included velocity, density, neutron porosity, resistivity, and 3-component magnetometer. The $222 \mathrm{~m}$ of basaltic penetration at Site 768 is the deepest ever into crust of back-arc origin and is the only significant amount of back-arc crust ever logged. The $106 \mathrm{~m}$ of crust logged at Site 770 surpasses all but a handful of DSDP and ODP sites and partially bridges the major gap between 6 and $110 \mathrm{Ma}$ in the in-situ measurement of geophysical properties of oceanic crust.

Although velocity logs at the two sites identify substantial velocity heterogeneity, the $3-5 \mathrm{~km} / \mathrm{s}$ velocities at Site 768 and the $4-5 \mathrm{~km} / \mathrm{s}$ velocities at Site 770 are broadly consistent with the velocity/age pattern of Houtz and Ewing (1976). These results, however, are not necessarily consistent with the standard model, which requires the velocity increase to result from crustal alteration. Instead, the Site 770 basalts appear to be less altered and more massive than the Site 768 basalts. Therefore, this paper examines the physical properties of both log and core samples from the two sites, to establish the interrelations among primary porosity, alteration, and velocity.

\section{GEOPHYSICAL LOGS AND THEIR CONTROLS}

\section{Log Interrelations}

The velocity, resistivity, density, and neutron-porosity logs are based on very different physical principles, yet each responds in its own way to the same three geological parameters: porosity, rock matrix, and pore fluids. Thus, plots of these four "geophysical logs" as a function of depth show substantial character similarity (Figs. 1 and 2), although the units of each log are totally 
R. D. JARRARD, C. BROGLIA

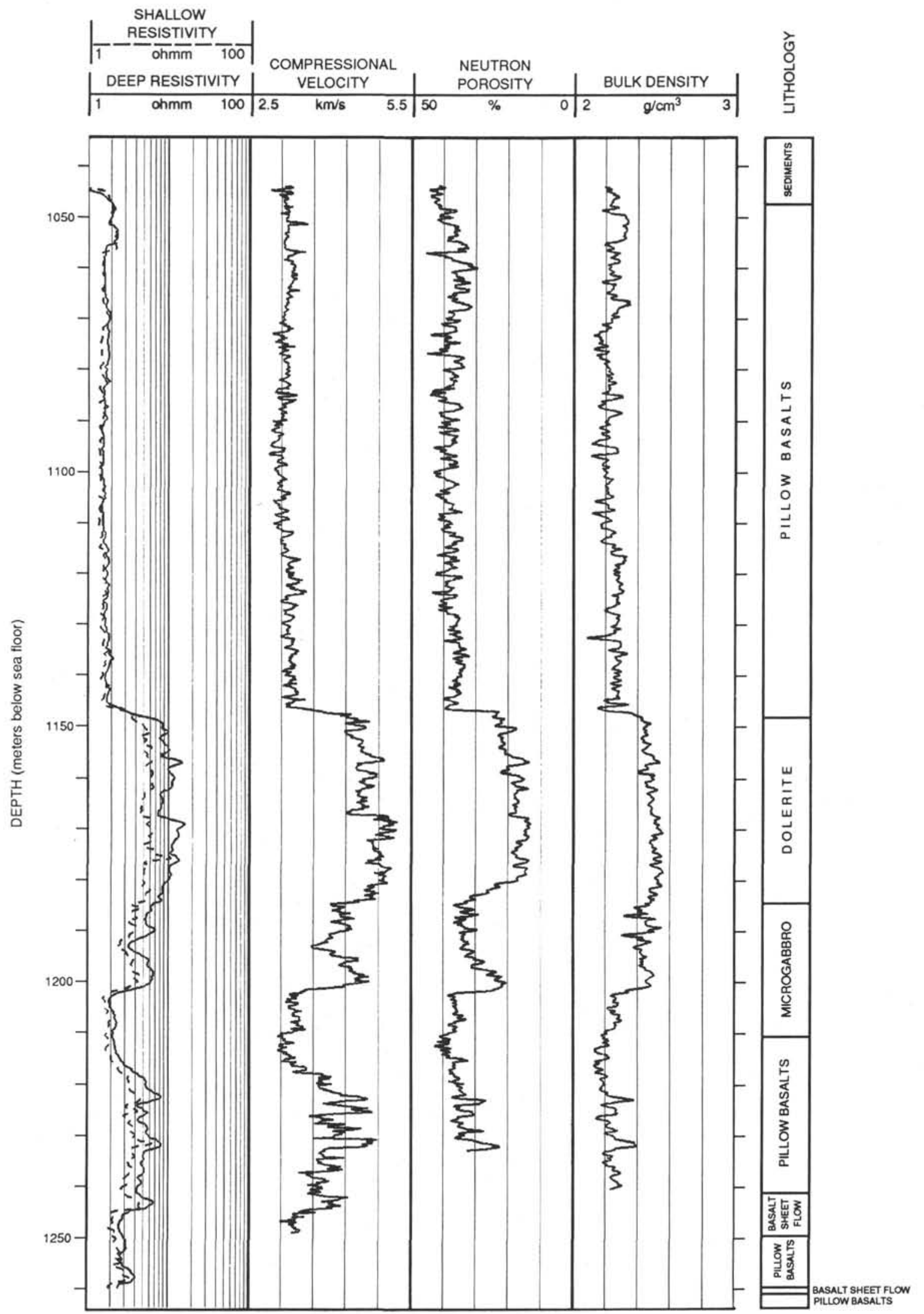

Figure 1. Original logs of resistivity (shallow and deep), velocity, neutron porosity, and bulk density for the crustal section drilled at Site 768. 


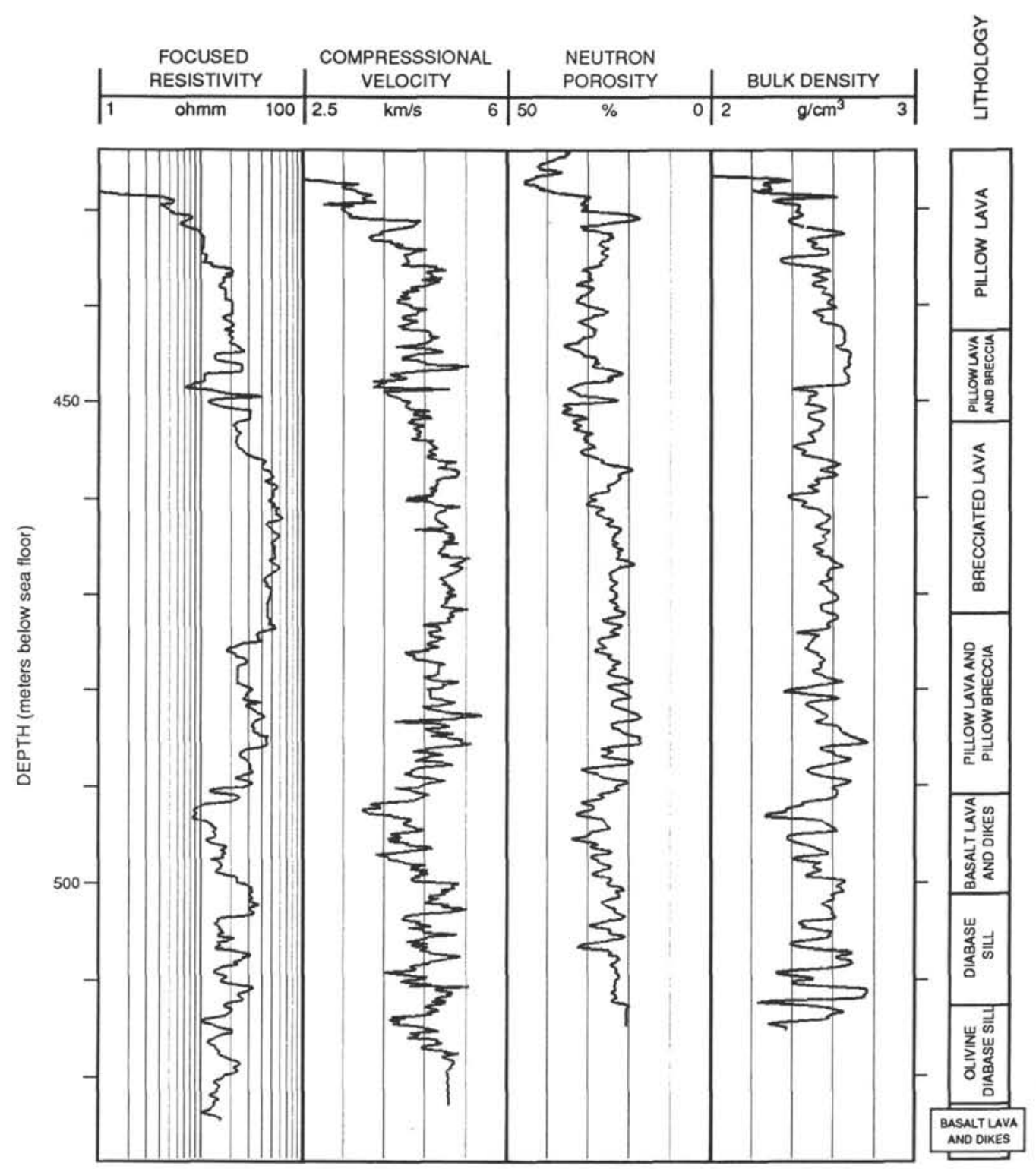

Figure 2. Original logs of resistivity (shallow focused), velocity, neutron porosity, and bulk density for the crustal section drilled at Site 770 .

different. This apparent redundancy between logs is an asset in our study of geophysical properties of oceanic crust because it allows us to evaluate the substantial variations in log quality and reliability that can occur between sites and even over distances of meters within a site.

The four log types differ dramatically in their sensitivity to pore fluids, rock matrix, and porosity. In deep-sea basalts, the pore space is filled by seawater of relatively uniform salinity; only the resistivity $\log$ shows a substantial sensitivity to pore-fluid variations, due to the effect of temperature on fluid resistivity. Although basalt composition varies substantially at the two sites, the only substantial variation in rock matrix from the log-response standpoint is the amount of clay alteration minerals. All four logs are somewhat sensitive to the amount of clay. Porosity is the most important control on the four log types, at least in basalts. Indeed, the velocity, density, and neutron porosity logs are often referred to as porosity logs.
Theoretical equations are well established for the transformation between geophysical log responses and their controlling geological parameters. These equations, however, contain some "local" parameters that must be empirically determined, based on interrelations between the geophysical and geological parameters when both are known. In the analyses that follow, we shall often use core measurements for determination of these "local constants." In doing so, we draw on a great potential strength of core measurements: the ability to make multiple nondestructive measurements of different types on exactly the same core sample. By using the core-derived constants in the analysis of continuous logs, we can largely avoid the great weakness of core measurements: discrete small-volume (usually about $10 \mathrm{~cm}^{3}$ ) samples are not representative because of vertical heterogeneity, preferential core recovery, and removal from in-situ conditions to laboratory temperatures and pressures. 


\section{Velocity}

The basalt intervals at Sites 768 and 770 were logged with the Schlumberger long-spaced sonic tool. This tool utilizes two sources and two receivers to generate four source-receiver transit times at each measurement point $(0.15 \mathrm{~m}$ apart $)$ over distances of $2.44,3.05,3.05$, and $3.66 \mathrm{~m}$. Transit time differences among these measurements yield vertical compressional-wave transit times (the inverse of velocity) with a vertical resolution of $0.6 \mathrm{~m}$. The principles and limitations of the tool are discussed elsewhere (e.g., Serra, 1984). Of particular interest here is that the tool was run at Sites 768 and 770 without centralization or standoffs. Thus a varying but substantial portion (often $20 \%-60 \%$ ) of the redundant measurements at each depth was obviously unreliable (Shipboard Scientific Party, 1990b and 1990c) due to cycle skips and "road noise" (reverberations due to tool drag over rough borehole wall). For both sites, a simple reprocessing algorithm (Shipboard Scientific Party, 1987) rejected the unreliable data, permitting recalculation of velocity logs (Figs. 1 and 2) that we consider to be generally reliable and virtually free of residual cycle skips and road noise (Shipboard Scientific Party, 1990b and 1990c). We suspect, however, that some of the spiky character in Site 770 velocities may be noise, particularly because its character is not consistently evident on the other geophysical logs. Sonic waveforms were recorded during data acquisition, and we could have utilized semblance analysis on these waveforms to calculate even more reliable velocity logs. However, we judged that the probable incremental improvement would be insufficient to justify the substantial time required as well as the degradation of vertical resolution to less than other log types.

By far the most important variable controlling velocity in these basalts is porosity. This control is evident in core measurements from the two sites (Fig. 3). We use shipboard measurements of compressional velocity, but not of porosity. In a companion paper, Jarrard and Schaar (this volume) redetermined the porosities of these samples, concluding that shipboard porosity measurements failed to dry the samples sufficiently and therefore underestimated porosity. The difference in porosity measurements has a dramatic impact on the apparent strength of the relation of porosity to velocity (Fig. 3), clearly indicating the greater reliability of the shore-based measurements.

The basalt samples from Site 770 are generally higher in velocity and lower in porosity than those from Site 768 (Fig. 3). This core-based pattern is consistent with the generally higher $\log$ velocities at Site 770 than at Site 768 (Figs. 1 and 2). The pattern indicates that the difference in measured log velocities between the two sites is caused by the higher microscale porosity at Site 768 . However, substantial vertical variation in logged velocity and therefore porosity is evident within the crustal section drilled at both sites (Figs. 1 and 2). In particular, sills are readily distinguishable from pillow basalts, evidently because of the much higher porosity in the latter.

In comparing core and log measurements of velocity in these basalts, considerable caution is required because of the much different volumes measured and particularly the nonrepresentativeness of core sampling. Core recovery in the basalts averaged $56.7 \%$ at Hole $768 \mathrm{C}$ and $42.8 \%$ at Hole $770 \mathrm{C}$, and the coring process tends to bias basalt core recovery toward fresher, less-altered basalts. Perhaps more important, much of the porosity in pillow basalts may be in the form of large-scale voids, fractures, and fracture filling that are unsampled by $10-\mathrm{cm}^{3}$ core plugs. Rebound, the core expansion that accompanies change from insitu to laboratory pressures (Hamilton, 1976), is probably minor in basalts. In general, the combination of these factors leads one to expect log velocities to be consistent with or slightly lower than
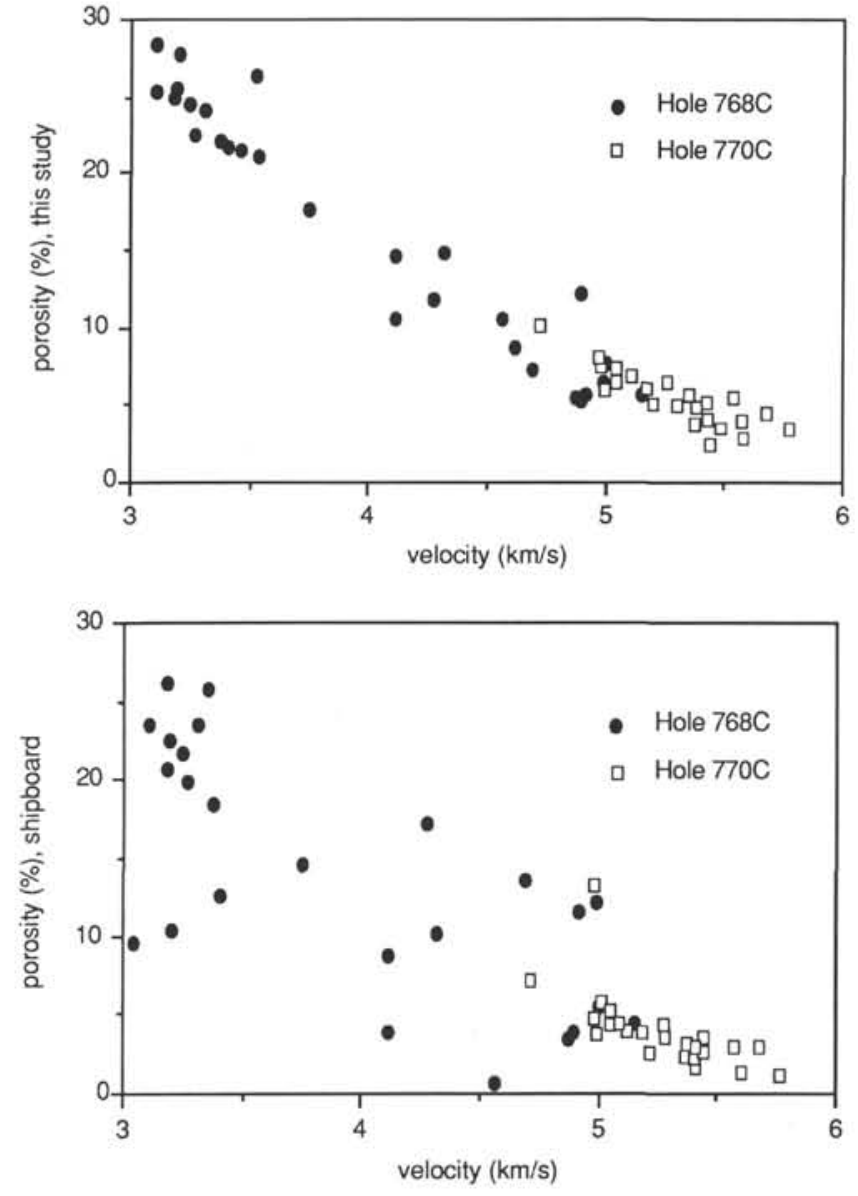

Figure 3. Relationship of compressional-wave velocity to porosity, from discrete core measurements of Sites 768 and 770 (from Jarrard and Schaar, this volume). The upper plot yields a much closer relationship of velocity to porosity than does the lower one, indicating that the shore-based porosity measurements are more accurate than the shipboard porosity measurements.

core velocities in massive units, and significantly lower than core velocities in pillows.

Figures 4 and 5 compare log velocities to core velocities at Sites 768 and 770 . In general, the two types of velocity measurement are remarkably similar at Site 768 (Fig. 4), both in the low-velocity pillows and in the high-velocity sills. The velocity log is particularly good at distinguishing pillows from the massive sills, in demonstrating that similar pillows underlie the sills in the interval 1202-1218 mbsf, and in detecting thin massive flows below 1218 mbsf. Unlike Site 768, Site 770 core velocities tend to be significantly higher than log velocities. We cannot account for this discrepancy, as both data types appear to us to be generally reliable. We will return to this question later, when we consider the consistency of other core and log data at Site 770 .

Sonic transit time ( $\Delta t$, usually expressed in $\mu \mathrm{s} / \mathrm{ft}$ ), depends on fractional porosity $(\phi)$, fluid transit time $\left(\Delta t_{f}\right.$ and matrix transit time $\left(\Delta t_{m a}\right)$ according to the Wyllie et al. (1956) equation:

$$
\begin{aligned}
& \Delta t=\Delta t_{m a} \cdot(1-\varphi)+\Delta t_{f} \cdot \varphi \text { or } \\
& \varphi=\Delta t /\left(\Delta t_{f}-\Delta t_{m a}\right)-\Delta t_{m d}\left(\Delta t_{f}-\Delta t_{m a}\right)
\end{aligned}
$$

Matrix transit times for basalts have been estimated by other investigators (e.g., Serra, 1986). Here we choose instead to use core measurements of velocity (expressed as transit time, its inverse) and 


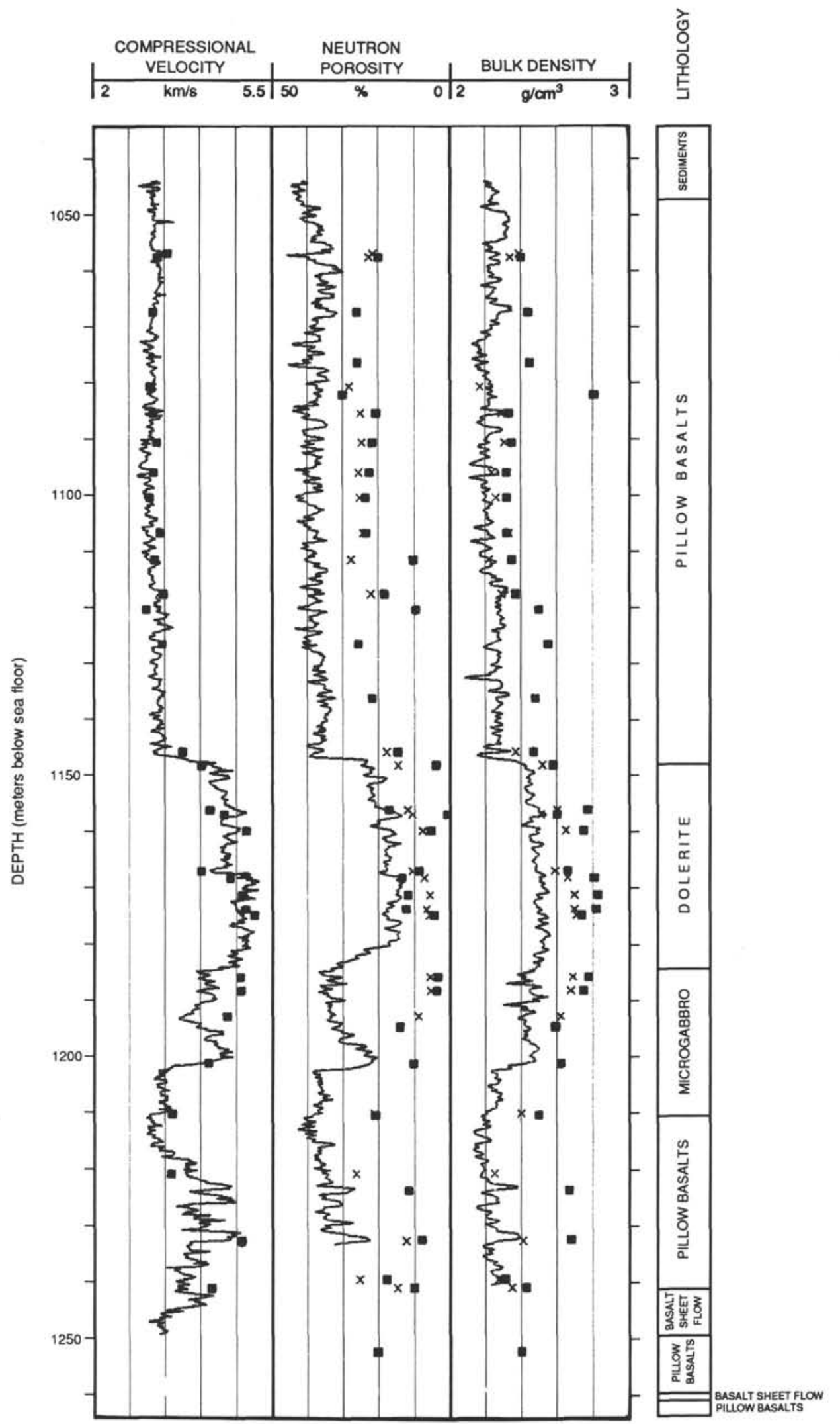

Figure 4. Comparison of original logs of velocity, neutron porosity, and bulk density at Site 768 to discrete measurements on cores. As shown in Figure 3, shore-based measurements (crosses) of porosity and density are more reliable than shipboard measurements (squares). 


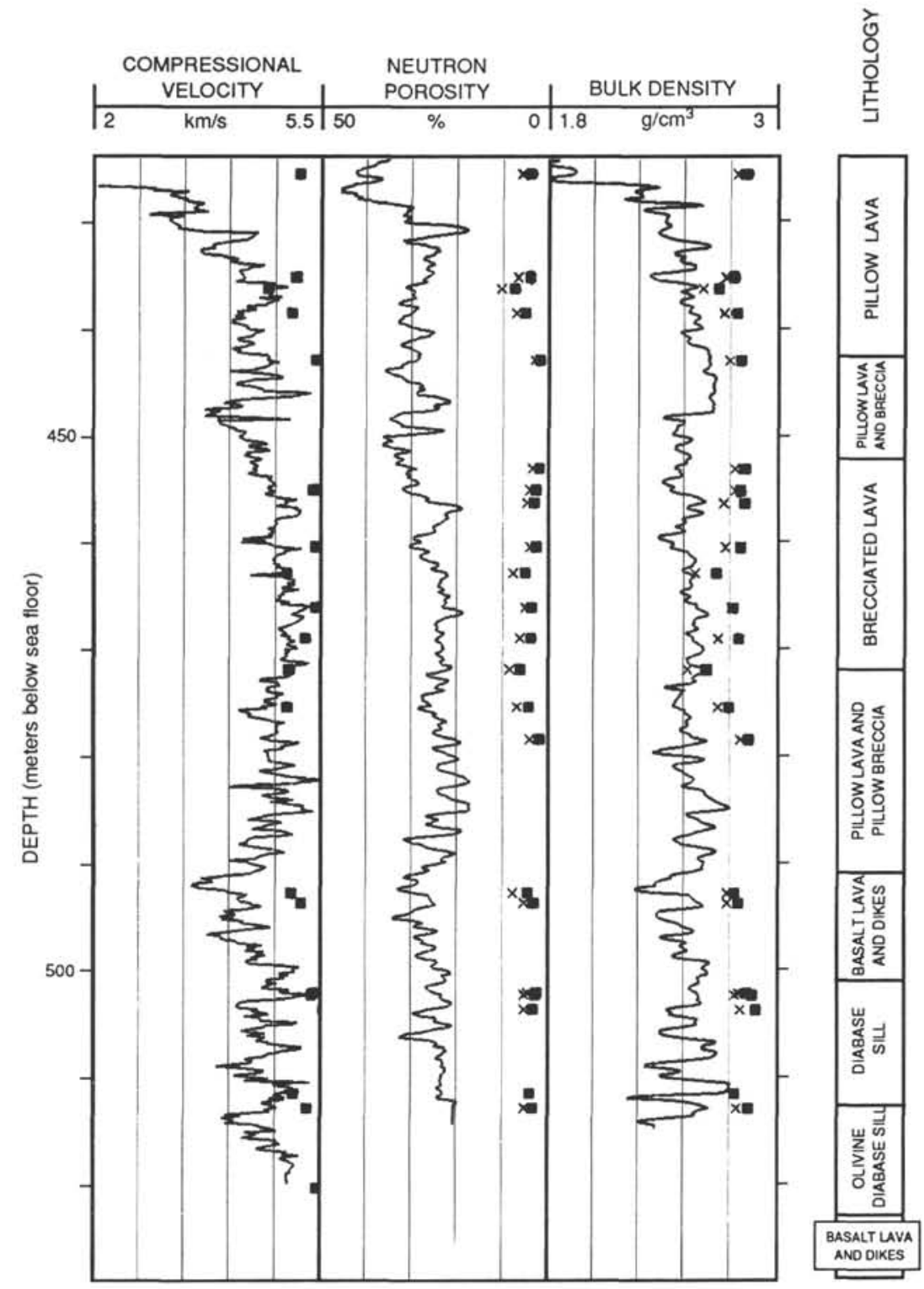

Figure 5. Comparison of original logs of velocity, neutron porosity, and bulk density at Site 770 to discrete measurements on cores. As shown in Figure 3, shore-based measurements (crosses) of porosity and density are more reliable than shipboard measurements (squares).

porosity (Table 1) and solve a regression equation with porosity as the dependent variable and transit time as the sole independent variable. Equation (1) above is of the same form as our regression equation, if one assumes constant matrix velocity and fluid velocity. Actually, matrix velocity probably varies slightly within these basalts due to changes in composition (particularly proportion of mafic minerals) and, more importantly, variations in extent of alteration. Further, fluid velocity varies slightly due to drilling mud and temperature variations. Note that prediction of porosity from transit time requires porosity to be treated as the dependent variable in the regression; this approach does not imply that transit time controls porosity.

Based on regression of core data at Site 768 (Fig. 6), transit time is related to fractional porosity (not percentage porosity as in Fig. 6) according to the relation:

$$
\varphi=0.00556 \cdot \Delta t-0.273 \quad R=0.97
$$

At Site 770 (Fig. 6), the relation is

$$
\varphi=0.00568 \cdot \Delta t-0.273 \quad R=0.90
$$

We consider the Site 768 relation to be better determined, based both on its higher correlation coefficient and on the much larger range of velocities and porosities. At both sites we see a more linear relationship, and correspondingly higher correlation coefficient, of porosity to transit time (Fig. 6) than to velocity (Fig. 3), consistent with prediction from the Wyllie relationship. Using the regression coefficients of equations (2) and (3) in conjunction with the Wyllie relationship of equation (1), we calculate that fluid transit time ( $\Delta \mathrm{tf})$ is $228.9 \mu \mathrm{s} / \mathrm{ft}$ at Site 768 and $224.2 \mu \mathrm{s} / \mathrm{ft}$ at Site 770 ; similarly, matrix transit time $\left(\Delta t_{m a}\right)$ is 49.1 $\mu \mathrm{s} / \mathrm{ft}$ at Site 768 and $48.1 \mu \mathrm{s} / \mathrm{ft}$ at Site 770 . These fluid transit times are slightly slower than the $210-220 \mu \mathrm{s} / \mathrm{ft}$ that we usually estimate 
Table 1. Physical property measurements at Holes $768 \mathrm{C}$ and $770 \mathrm{C}$.

\begin{tabular}{|c|c|c|c|c|c|}
\hline $\begin{array}{l}\text { Core-sec. } \\
(\mathrm{cm})\end{array}$ & $\begin{array}{l}\text { Depth } \\
\text { (mbsf) }\end{array}$ & $\begin{array}{l}\text { Bulk density } \\
\qquad\left(\mathrm{g} / \mathrm{cm}^{3}\right)\end{array}$ & $\begin{array}{l}\text { Grain density } \\
\left(\mathrm{g} / \mathrm{cm}^{3}\right)\end{array}$ & $\begin{array}{l}\text { Porosity } \\
(\%)\end{array}$ & $\begin{array}{l}\text { Velocity } \\
(\mathrm{km} / \mathrm{s})\end{array}$ \\
\hline \multicolumn{6}{|l|}{ Hole $768 \mathrm{C}$} \\
\hline $74-1-115$ & 1057.45 & 2.39 & 2.76 & 21.5 & 3.46 \\
\hline $74-2-37$ & 1058.12 & 2.34 & 2.73 & 22.6 & 3.27 \\
\hline $77-1-48$ & 1081.08 & 2.17 & 2.62 & 28.3 & 3.11 \\
\hline $78-1-27$ & 1085.87 & 2.29 & 2.72 & 25.0 & 3.18 \\
\hline $79-1-38$ & 1090.98 & 2.31 & 2.73 & 24.6 & 3.25 \\
\hline $80-1-77$ & 1096.37 & 2.24 & 2.65 & 25.5 & 3.19 \\
\hline $81-1-19$ & 1100.79 & 2.26 & 2.68 & 25.3 & 3.11 \\
\hline $82-2-17$ & 1107.22 & 2.33 & 2.74 & 24.2 & 3.31 \\
\hline $83-1-137$ & 1111.97 & 2.22 & 2.67 & 27.7 & 3.20 \\
\hline $84-2-93$ & 1118.03 & 2.29 & 2.65 & 22.1 & 3.37 \\
\hline $88-1-28$ & 1146.28 & 2.37 & 2.66 & 17.7 & 3.75 \\
\hline $88-2-114$ & 1148.46 & 2.52 & 2.78 & 14.5 & 4.11 \\
\hline $89-1-77$ & 1156.47 & 2.60 & 2.81 & 11.8 & 4.28 \\
\hline $89-2-5$ & 1157.25 & 2.51 & 2.68 & 10.6 & 4.56 \\
\hline $89-4-50$ & 1160.12 & 2.65 & 2.79 & 7.7 & 5.00 \\
\hline $90-2-59$ & 1167.20 & 2.59 & 2.78 & 10.5 & 4.11 \\
\hline $90-3-50$ & 1168.41 & 2.66 & 2.79 & 7.2 & 4.69 \\
\hline $90-5-72$ & 1171.49 & 2.70 & 2.79 & 5.6 & 4.92 \\
\hline $90-7-104$ & 1174.12 & 2.70 & 2.82 & 6.5 & 4.99 \\
\hline $91-1-32$ & 1175.22 & 2.71 & 2.81 & 5.7 & 5.15 \\
\hline $92-2-22$ & 1186.17 & 2.69 & 2.79 & 5.5 & 4.88 \\
\hline $92-3-135$ & 1188.55 & 2.68 & 2.78 & 5.3 & 4.90 \\
\hline $93-2-12$ & 1193.12 & 2.62 & 2.77 & 8.8 & 4.62 \\
\hline $95-1-4$ & 1210.44 & 2.40 & 2.76 & 21.1 & 3.54 \\
\hline $96-1-106$ & 1221.06 & 2.25 & 2.69 & 26.3 & 3.52 \\
\hline $97-3-65$ & 1233.11 & 2.41 & 2.60 & 22.2 & 4.90 \\
\hline $98-1-48$ & 1239.88 & 2.27 & 2.69 & 25.3 & \\
\hline $98-2-54$ & 1241.44 & 2.35 & 2.57 & 24.7 & 4.32 \\
\hline $99-3-98$ & 1252.92 & 2.32 & 2.72 & 24.0 & \\
\hline $100-1-36$ & 1259.16 & 2.22 & 2.55 & 21.7 & 3.41 \\
\hline \multicolumn{6}{|l|}{ Hole $770 \mathrm{C}$} \\
\hline $2-20-80$ & 4941.70 & 2.80 & 2.91 & 5.8 & 5.17 \\
\hline $3-2-72$ & 4951.32 & 2.74 & 2.86 & 6.6 & 5.12 \\
\hline $3-3-23$ & 4952.33 & 2.62 & 2.80 & 10.3 & 4.69 \\
\hline $3-4-102$ & 4954.62 & 2.73 & 2.86 & 6.9 & 5.05 \\
\hline $4-1-29$ & 4959.09 & 2.76 & 2.82 & 2.9 & 5.42 \\
\hline $5-1-67$ & 4969.08 & 2.79 & 2.85 & 3.3 & 5.58 \\
\hline $5-3-40$ & 4971.16 & 2.79 & 2.86 & 3.9 & 5.39 \\
\hline $5-4-37$ & 4972.39 & 2.73 & 2.81 & 4.5 & 5.66 \\
\hline $5-7-27$ & 4976.41 & 2.74 & 2.81 & 4.0 & 5.42 \\
\hline $6-1-82$ & 4978.92 & 2.58 & 2.71 & 7.6 & 4.98 \\
\hline $6-3-116$ & 4982.10 & 2.77 & 2.87 & 5.0 & 5.42 \\
\hline $6-5-107$ & 4985.01 & 2.70 & 2.81 & 6.1 & 5.27 \\
\hline $7-1-27$ & 4987.97 & 2.54 & 2.67 & 8.3 & 5.01 \\
\hline $7-3-84$ & 4991.37 & 2.70 & 2.82 & 6.7 & 4.99 \\
\hline $7-5-107$ & 4994.41 & 2.82 & 2.89 & 4.0 & 5.76 \\
\hline $9-2-29$ & 5008.79 & 2.75 & 2.89 & 7.5 & 5.06 \\
\hline $9-2-120$ & 5009.70 & 2.75 & 2.84 & 5.1 & 5.21 \\
\hline $10-1-140$ & 5018.10 & 2.81 & 2.89 & 4.4 & 5.39 \\
\hline $10-2-29$ & 5018.29 & 2.79 & 2.89 & 5.1 & 5.37 \\
\hline $10-3-8$ & 5019.67 & 2.82 & 2.92 & 5.2 & 5.55 \\
\hline $11-2-99$ & 5028.72 & 2.80 & 2.90 & 5.1 & 5.30 \\
\hline $12-1-8$ & 5036.18 & 2.82 & 2.89 & 3.6 & 5.46 \\
\hline $12-2-66$ & 5038.26 & 2.80 & 2.87 & 3.7 & 5.57 \\
\hline
\end{tabular}

for mud-filled ODP holes, whereas matrix transit times are consistent with estimates of Serra (1986). At neither site do we see any tendency for samples subjectively rated as moderately altered to be higher in porosity and lower in velocity than samples judged to be slightly altered. The highly altered samples at Site 768, however, are substantially lower in velocity and higher in porosity than less-altered samples. Further, samples at Site 768 are generally somewhat more altered than at Site 770 . These patterns are consistent with concepts of crustal alteration: more porous zones are expected to be higher in primary permeability, and therefore in hydrothermal circulation, and therefore in associated basalt alteration. Jarrard and Schaar (this volume) measured cation exchange capacity (CEC) on these core samples, obtaining a more objective measure of alteration. These data yield the same general
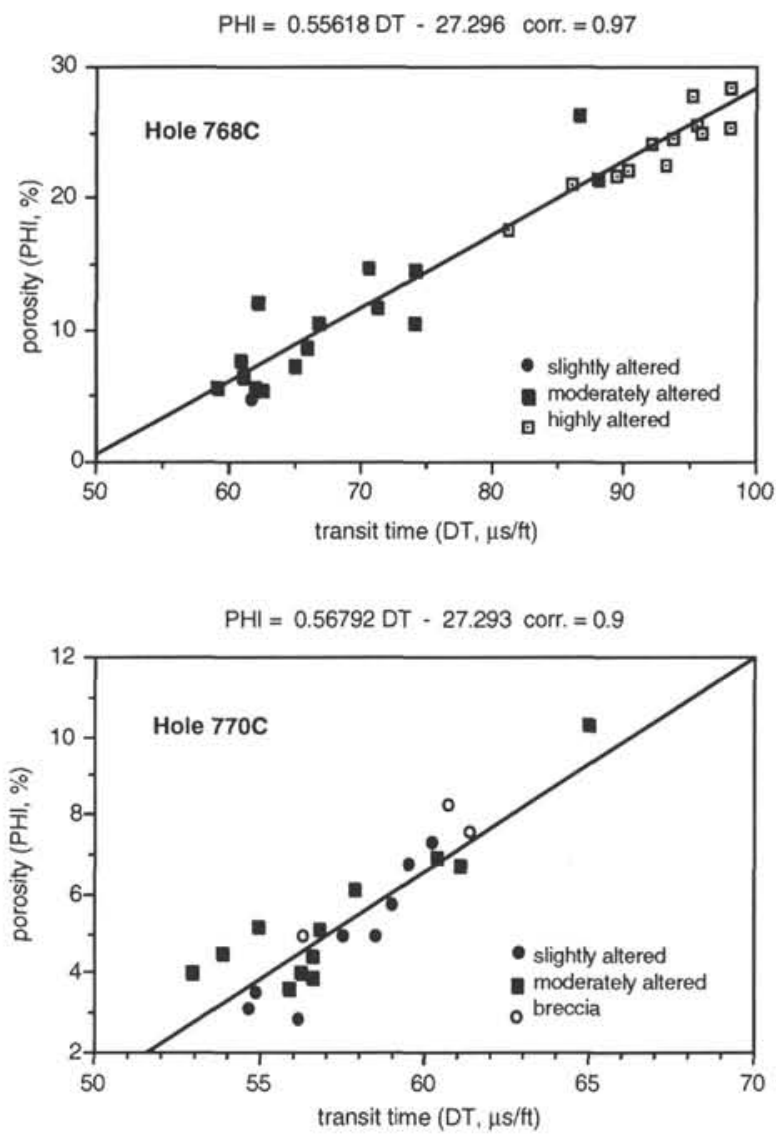

Figure 6. Relationship of transit time (inverse of velocity) to porosity for discrete-core measurements at Sites 768 (top) and 770 (bottom).

pattern of greater clay content in the more porous basalts, with one exception: they find one interval with high CEC in the low-porosity, high-velocity basalts at Site 770 .

The regression coefficients at the two sites are remarkably similar, and an overlay of both sites (Fig. 3) demonstrates that both predominantly fit the same overall pattern. Nevertheless, we use the site-specific regressions rather than the overall average regression to transform velocity logs into porosity logs for the two sites (Figs. 7 and 8). Equations (2) and (3) indicate slightly less sensitivity of velocity to porosity change than the similar velocity/porosity relationships determined from Hole 395A basalt cores by Hyndman et al. (1984) and from Hole 418A basalt logs by Broglia and Moos (1988). Also, our relationships indicate much less sensitivity of velocity to porosity change than the core analyses of Christensen et al. (1979).

Sonic-derived porosity at the two sites ranges from $25 \%$ in the pillows at Site 768 to about $5 \%$ in massive parts of the sills at both sites. Sonic porosities at Site 770 tend to be about $5 \%$ higher than core porosities. This pattern is similar to and consistent with that previously observed in the pattern of log and core velocities. In spite of this unexplained discrepancy at Site 770, we consider the two sonic porosity logs to be our best estimate of the in-situ porosity structure of the upper oceanic crust at the two sites.

The Wyllie relationship is based on so simple a conceptual picture of sound propagation in porous media that it is often called an empirical relationship rather than a theoretical one. In particular, it ignores pore aspect ratio. The relation of Gassmann (1951) and particularly those of Kuster and Toksöz (1974) and Toksöz et al. (1976) are more theoretically satisfying but less useful for our purposes because of their needs for additional parameters 


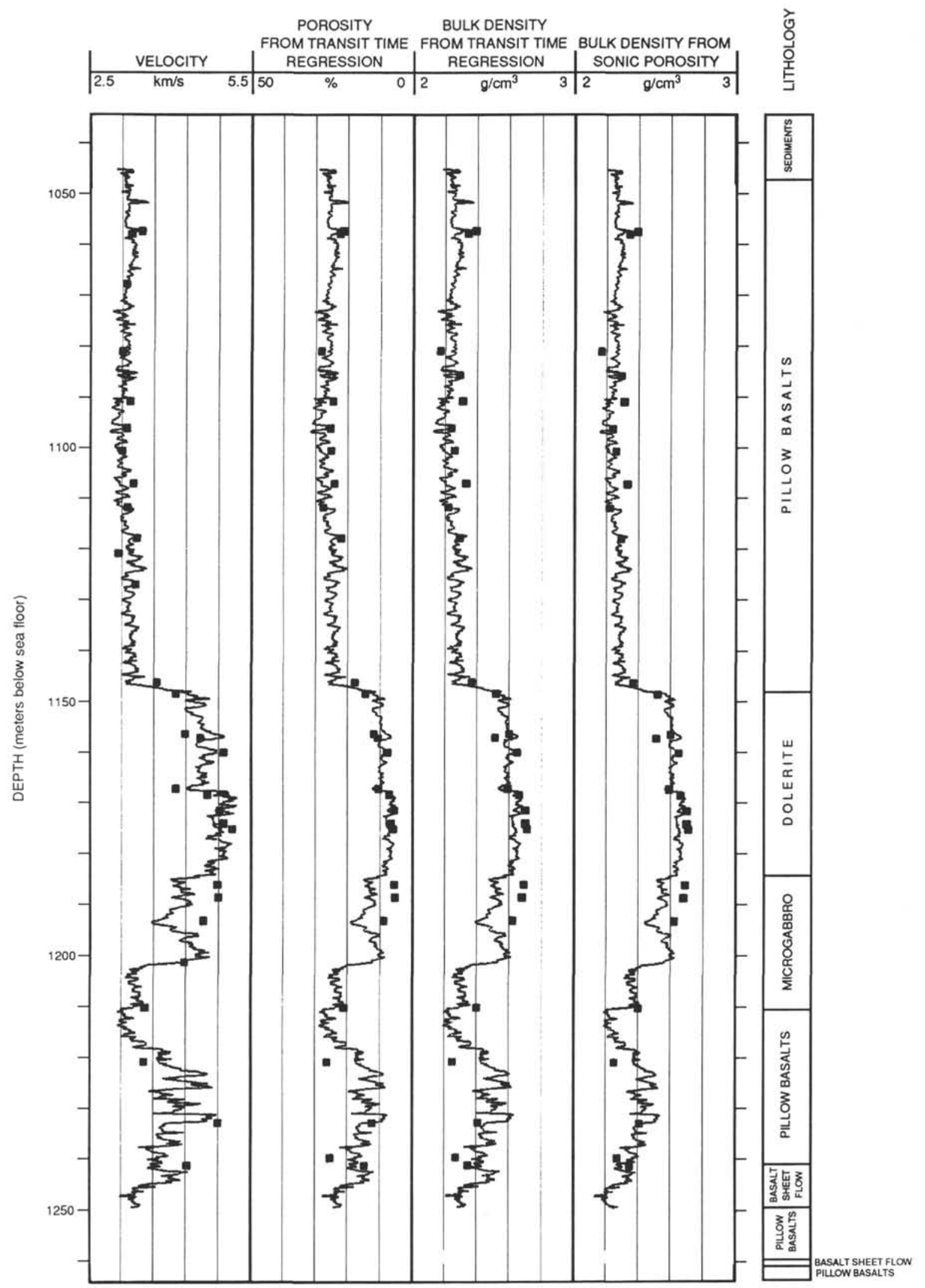

Figure 7. Velocity-derived logs from Site 768 show good agreement with shore-based core measurements. 


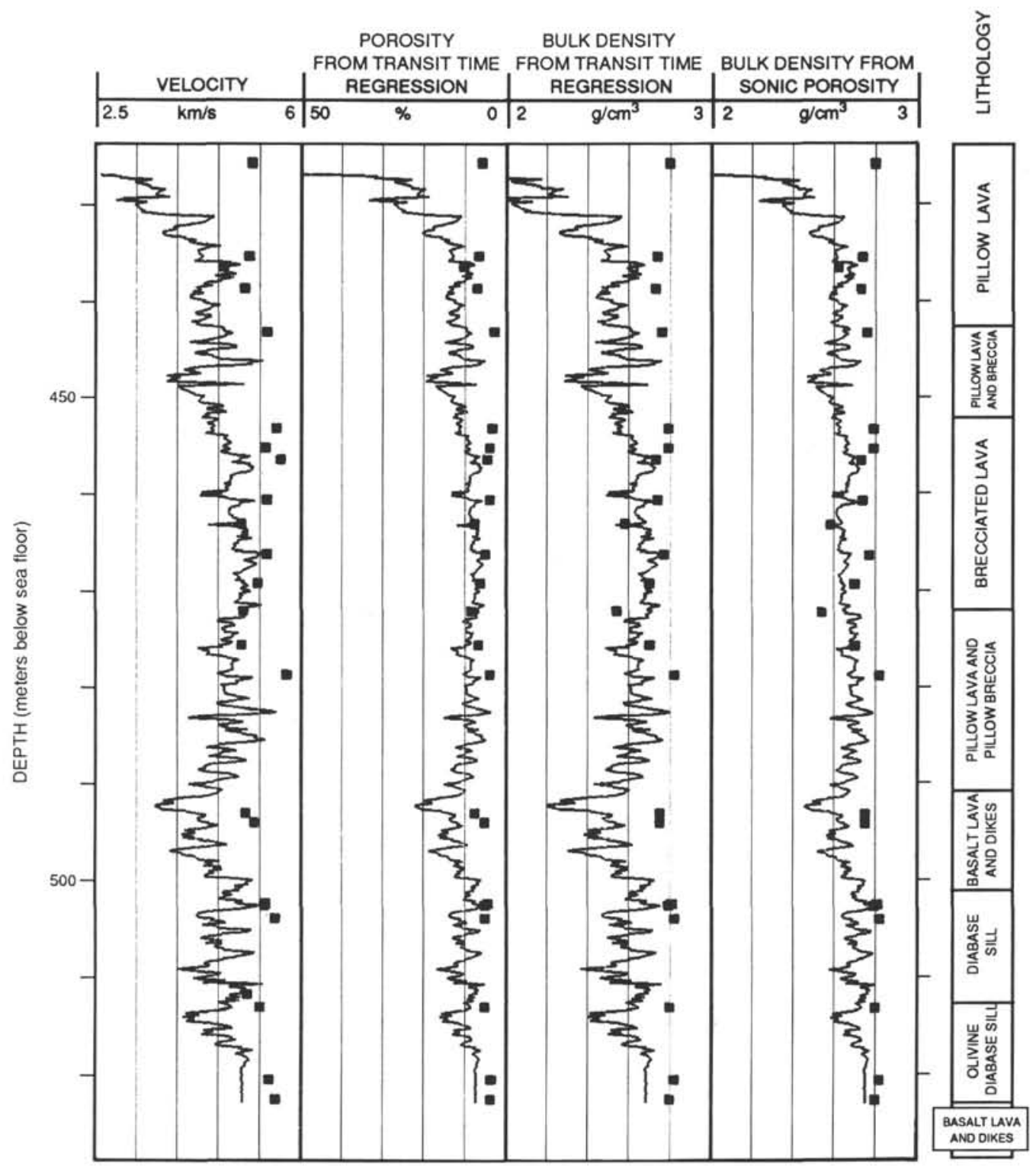

Figure 8 . Velocity-derived logs from Site 770 show only moderate agreement with shore-based core measurements.

(e.g., elastic moduli). The Wyllie relationship does appear to be quite successful empirically at Sites 768 and 770 . However, we should remember that in applying core-based regression parameters to the calculation of log-based porosity, we are implicitly assuming that pore aspect ratios are generally similar in cores and logs. In discussions of resistivity in the next section, we will find evidence that this assumption is surprisingly good.

\section{Resistivity}

Three resistivity logs with different depths of penetration (shallow, medium, and deep) were obtained at each site (Shipboard Scientific Party, 1990b and 1990c). In general, resistivity logs are among the highest in signal-to-noise ratio of any log obtained in ODP. Unfortunately, this precision is not necessarily matched by accuracy; we observed consistent offsets among the three resistivity logs at each site, with the medium induction log yielding the highest apparent resistivity. We know of no plausible reason for this pattern; thermal gradients away from the borehole would cause a gradual decrease from shallow to medium to deep resistivity, while disturbance of the formation by drilling fluid could cause this pattern or its converse.

If clays have a minor contribution to measured formation resistivity $\left(R_{o}\right)$, then $R_{o}$ is related to porosity by the Archie (1942) equation, as generalized by Winsauer and McCardell (1953):

$$
F F=a \cdot \varphi^{-m}
$$

where the formation factor $F F$ is equal to the ratio of formation resistivity to resistivity of the formation water $\left(R_{w}\right)$. Estimation of equilibrium $R_{w}$ can be reasonably accurate if the equilibrium thermal gradient is known; it is not. Estimation of $R_{w}$ for the time of logging is even more difficult. We used the temperatures of borehole fluid measured by a temperature tool mounted on the same tool string as the resistivity tool (Shipboard Scientific Party, 1990b and 1990c). We recognize, however, that the actual average temperature of the formation near the borehole is likely to be intermediate between measured 
borehole temperatures and equilibrium formation temperatures. A $1{ }^{\circ} \mathrm{C}$ error in estimated temperature causes an approximately $2 \%$ error in $R_{w}$.

Surface conduction on clays can have a significant effect on basalt resistivity, particularly at elevated temperatures. Olhoeft (1981) concluded that surface conduction can be negligible at room temperature but is dominant over pore conductivity at temperatures above $80^{\circ} \mathrm{C}$. Based on this generalization, surface conduction could be substantial in the moderately hot and quite altered basalts of Site 768 . When clays are present, observed resistivity $\left(R_{o}\right)$ depends on the contributions of both pore fluids and clay surface conduction acting as two conductors in parallel according to the relation (Waxman and Smits, 1968; Pape et al., 1985):

$$
1 / R_{o}=F F / R_{w}+B \cdot C E C \cdot \rho_{b} \cdot(1-\varphi) /\left(\varphi \cdot \mu^{2} \cdot F F\right)
$$

where $F F$ is the "intrinsic" formation factor, $B$ is the sodium charge mobility, CEC is the cation exchange capacity, $\rho_{\mathrm{b}}$ is the bulk density, $\phi$ is the fractional porosity, and $\mu^{2}$ is a tortuosity factor. The intrinsic formation factor is the ratio $R_{w} / R_{o}$ that would have been obtained if the formation were saturated with fluid of sufficiently high salinity to permit pore conductivity to dominate clay conductivity. Because intrinsic formation factor is dependent on porosity according to equation (4), both the pore and clay portions of equation (5) are porosityrelated. Given resistivity and density logs, and given estimates of the "constants" $R_{w}, B$, and $\mu^{2}$, one still needs a CEC log before porosity can be determined.

Pezard (1990) utilizes equation (5), including a log of estimated clay content, to determine porosity from resistivity at Hole 504B. We used a two-fold approach here. First, we evaluated the extent to which it appears feasible to determine a log of estimated clay content from other logs at Sites 768 and 770 . Second, Jarrard and Schaar (this volume) measured resistivity and CEC of basalts at these sites and evaluated the relative importance of pore-fluid conduction and clay-surface conduction. We shall see that the second approach removes the need for the first one.

The potassium content of altered basalts is often an order of magnitude higher than that of fresh basalts, due to potassium absorption from seawater during the alteration process. Consequently, Broglia and Moos (1988) found that both the potassium log and total gamma-ray log at Hole $418 \mathrm{~A}$ were highly correlated with qualitative ratings of core alteration, making these logs good proxy indicators of variation in the content of potassium-rich alteration minerals at Hole $418 \mathrm{~A}$. Low-temperature alteration such as this does not always lead to such a simple pattern. Thus such a pattern cannot be assumed without direct evidence.

In Figures 9 and 10 we compare the potassium logs from the basalts at Sites 768 and 770 to core measurements of potassium oxide weight fraction and to three alteration estimates from cores. First, loss on ignition (LOI) during X-ray fluorescence measurements of basalts is often proportional to the amount of bound water in clays. Second, the total percentage of hydrous minerals identified in thin sections is a direct indication of extent of alteration, though subject to the qualifications that shipboard estimates of mineral percentages are qualitative, are not based on point counting, and that the thin sections are deliberately obtained from the least-altered rocks. The $\mathrm{LOI}$ and $\mathrm{K}_{2} \mathrm{O}$ weight fraction results shown here are those of the Shipboard Scientific Party (1990b and 1990c), revised by P. Spadea (pers. comm., 1990). The hydrous mineral visual estimates are from the Shipboard Scientific Party (1990b and 1990c). Third, Jarrard and Schaar (this volume) subjectively rated the extent of alteration in basalt samples that they studied.

Comparison of widely spaced and probably nonrepresentative discrete samples with continuous logs is imprecise but still useful.
At Site 768 (Fig. 9), the lower sill and lower part of the upper sill (1177-1202 mbsf) form a low-potassium zone according to the potassium log. Discrete measurements are generally consistent but indicate that all of both sills (1147-1202 mbsf) is substantially lower in potassium, loss on ignition, and alteration than the surrounding pillows. This pattern is consistent with the much greater porosity and permeability of the pillows, permitting greater hydrothermal alteration than in the sills. Beyond this simple dichotomy, however, little correlation between the log and core data of Site 768 is found. For the much shorter interval at Site 770 , neither the potassium log nor core potassium exhibits any correlation with the alteration indicators from core (Fig. 10). Both potassium and alteration at this site are consistently lower than at Site 768 , consistent with our velocity-derived porosities, which are lower at Site 770 than at Site 768. At neither site, however, does it appear to be valid to use the potassium log as a proxy indicator of amount of alteration minerals.

Jarrard and Schaar (this volume) measure resistivity as a function of temperature and salinity for the basalts of Sites 768 and 770. They find that a conductivity component independent of fluid conductivity is dominant at low salinities. For the range of fluid conductivities present in situ at the sites, corresponding to a salinity of $35 \mathrm{ppt}$ and temperatures of $10^{\circ}-50^{\circ} \mathrm{C}$ (Shipboard Scientific Party, 1990b and 1990c), they conclude that this component is detectable but so minor that it can be neglected without substantially biasing the estimate of porosity. This component is usually interpreted to be surface conduction on clays; however, they compare measurements of cation exchange capacity to the resistivity data and conclude that impermeable cracks may be more important than clays in creating this conductivity component independent of fluid conductivity. Regardless of the mechanism, we rely on their conclusion that pore fluids strongly dominate the rock conductivity, permitting us to relate porosity to resistivity according to equation (4) rather than equation (5).

We can use equation (4) to relate porosity to resistivity in one of two ways. First, we can use the values of the constants $a$ and $m$ determined by Jarrard and Schaar (this volume) based on measurements of both porosity and resistivity on basalt samples at the two sites; these coefficients permit conversion of the resistivity logs to porosity logs. Second, we can use the porosity logs based on velocity in conjunction with the resistivity log to estimate the coefficients $a$ and $m$. Because we are confident that we already have reliable porosity logs based on velocity, and because $a$ and $m$ are almost never estimated independently from both cores and logs for the same basalt interval, we chose the second approach of determining $a$ and $m$ from logs.

Figure 11 plots formation factor vs. porosity for the two sites, using logarithmic scaling so that a linear regression yields Archie's coefficients $a$ and $m$. At both sites, a strong correlation between formation factor and porosity is observed. This correlation is not surprising, as we have already seen a strong character match between resistivity and velocity logs plotted as a function of depth (Figs. 1 and 2). It is surprising that the relation observed at Site 768 is somewhat curved, unlike the linear relation expected theoretically and observed at Site 770. We do not know the reason for this slight curvature, but it is traceable to the lower half of the dolerite sill, which is higher in velocity but not higher in resistivity than the upper half of the sill (Fig. 1).

Linear regression yields $F F=2.22 \varphi^{-1.58}$ for Site 768 , and $F F=6.52 \varphi^{-1.15}$ for Site 770 . Though the coefficients seem substantially different at the two sites, the tradeoff between $a$ and $m$ is such that either fits the data from the other site reasonably well. In particular, if the highest porosity data at Site 768 were deleted, then the curvature would disappear, the two sites would span about the same porosity range, and the estimated coefficients for the two sites would be approximately the same. Site 768 , however, 


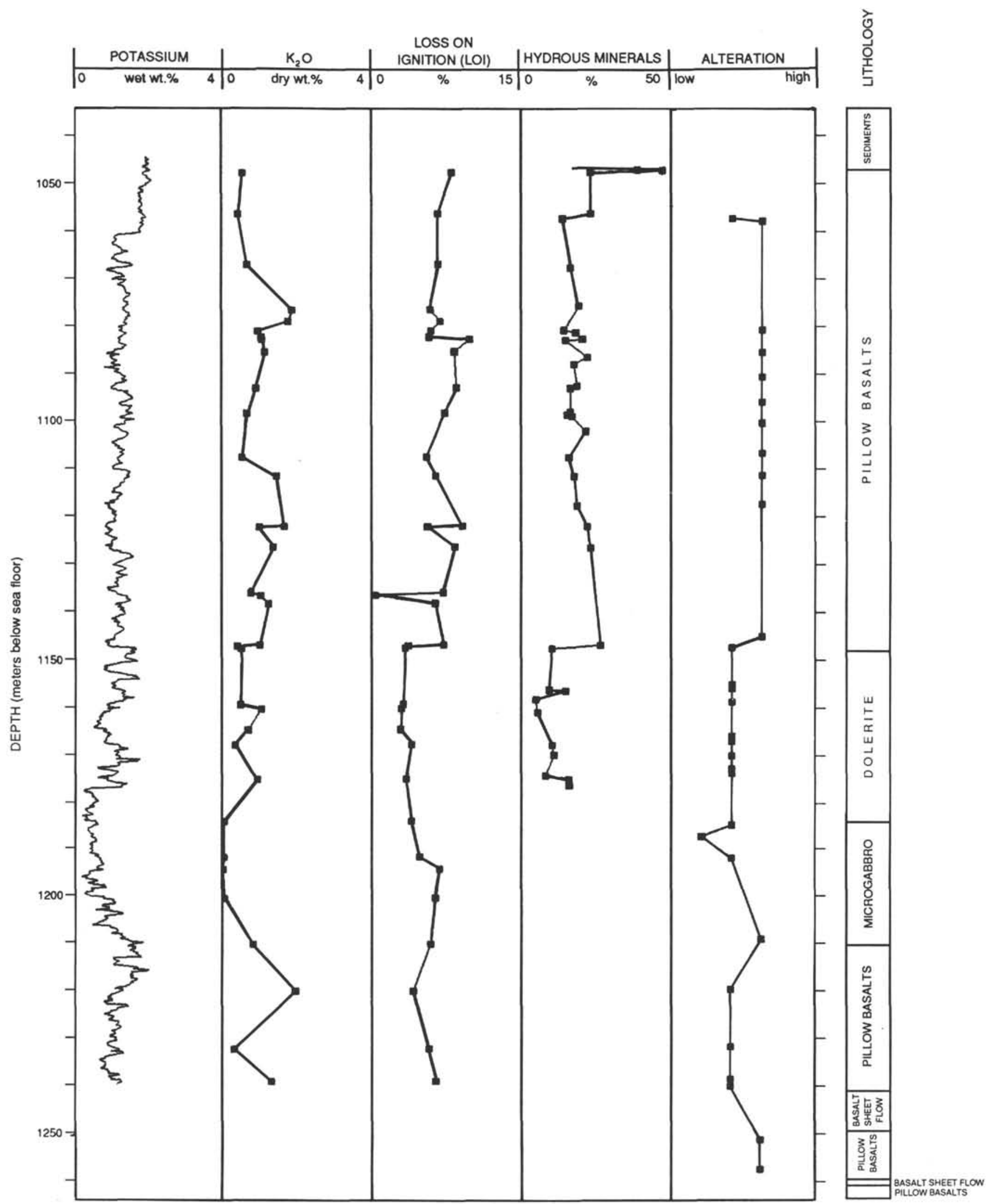

Figure 9. Comparison of the potassium log from Site 768 to core measurements of $\mathrm{K}_{2} \mathrm{O}$ weight fraction and to three alteration indicators (see text). Note that the potassium log cannot be used as a proxy log of alteration. 


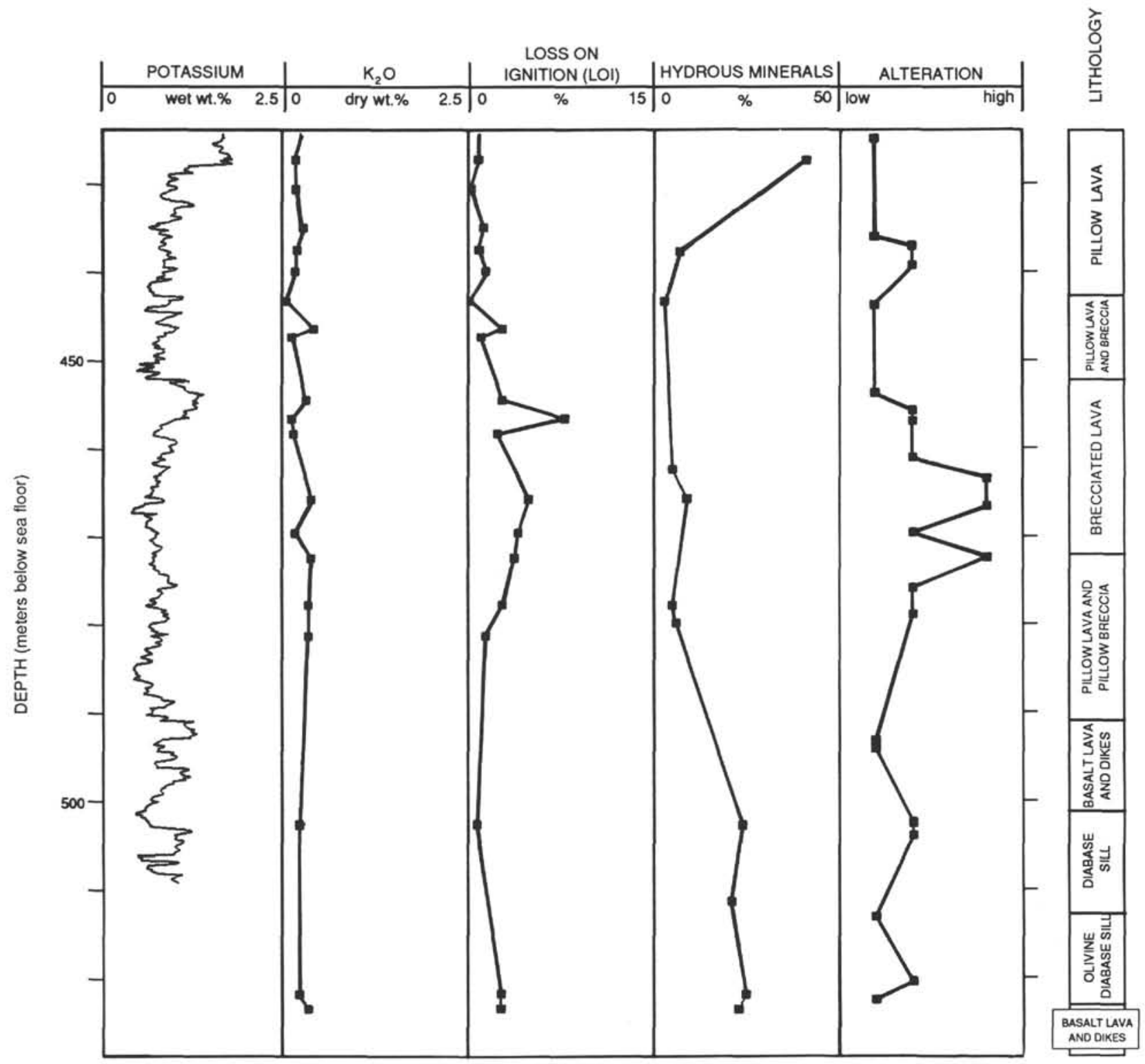

Figure 10. Comparison of the potassium $\log$ from Site 770 to core measurements of $\mathrm{K}_{2} \mathrm{O}$ weight fraction and to three alteration indicators (see text). Note that the potassium $\log$ cannot be used as a proxy log of alteration. Note also that Site 770 is lower in both potassium and alteration than Site 768 (Fig. 9).

has a higher correlation coefficient and larger range of porosities fit by regression, suggesting that its fit is better constrained than at Site 770 .

Jarrard and Schaar (this volume) determined $a$ and $m$ from regression of core data at these sites. They estimated $a$ and $m$ separately at three temperatures, $10^{\circ}, 25^{\circ}$, and $50^{\circ} \mathrm{C}$, and for two salinities, 29.5 and $87.6 \mathrm{ppt}$. Jarrard and Schaar (this volume) did not solve separately for the two sites, as they detected no systematic differences in electrical properties between the two, except for those attributable to the generally lower porosities at Site 770 than at Site 768. Based on the similarity of their estimates of $a$ and $m$ for such a wide range of salinity and temperature, they concluded that the slight effect of clay conduction can be ignored, and that a single set of coefficients $(R=0.91-0.934)$ well describes the relation between conductivity and porosity at the two sites. Their estimates of $a$ range from 2.4 to 4.8 , averaging 3.0 for salinity and temperatures appropriate in situ; this value is inter- mediate between our values of 2.2 and 6.5 for Site 768 and 770 logs, respectively. Jarrard and Schaar's (this volume) estimates for $m$ range from 1.31 to 1.44 , averaging 1.41 for salinity and temperature appropriate in situ; this value is intermediate between our values of 1.6 and 1.2 for Site 768 and $770 \mathrm{logs}$, respectively. In view of the very different techniques and assumptions of the core and log analyses, the extent of agreement is remarkable. In particular, the prime uncertainty of our log analysis is the estimation of formation temperature and therefore of fluid resistivity; the prime uncertainty of Jarrard and Schaar's (this volume) core analysis is the extent to which their 54 core samples are representative of the range of in-situ formation properties.

Several previous studies of basalt cores or logs have estimated $a$ and $m$ (e.g., summary by Pezard, 1990). For example, Broglia and Moos (1988) found from logs that $F F=11.5 \varphi^{-1.85}$ in the uppermost altered portion of Hole $418 \mathrm{~A}$, and $F F=29.5 \varphi^{-1.16}$ in the lower portion of that site. Similarly, Pezard (1990) found from 

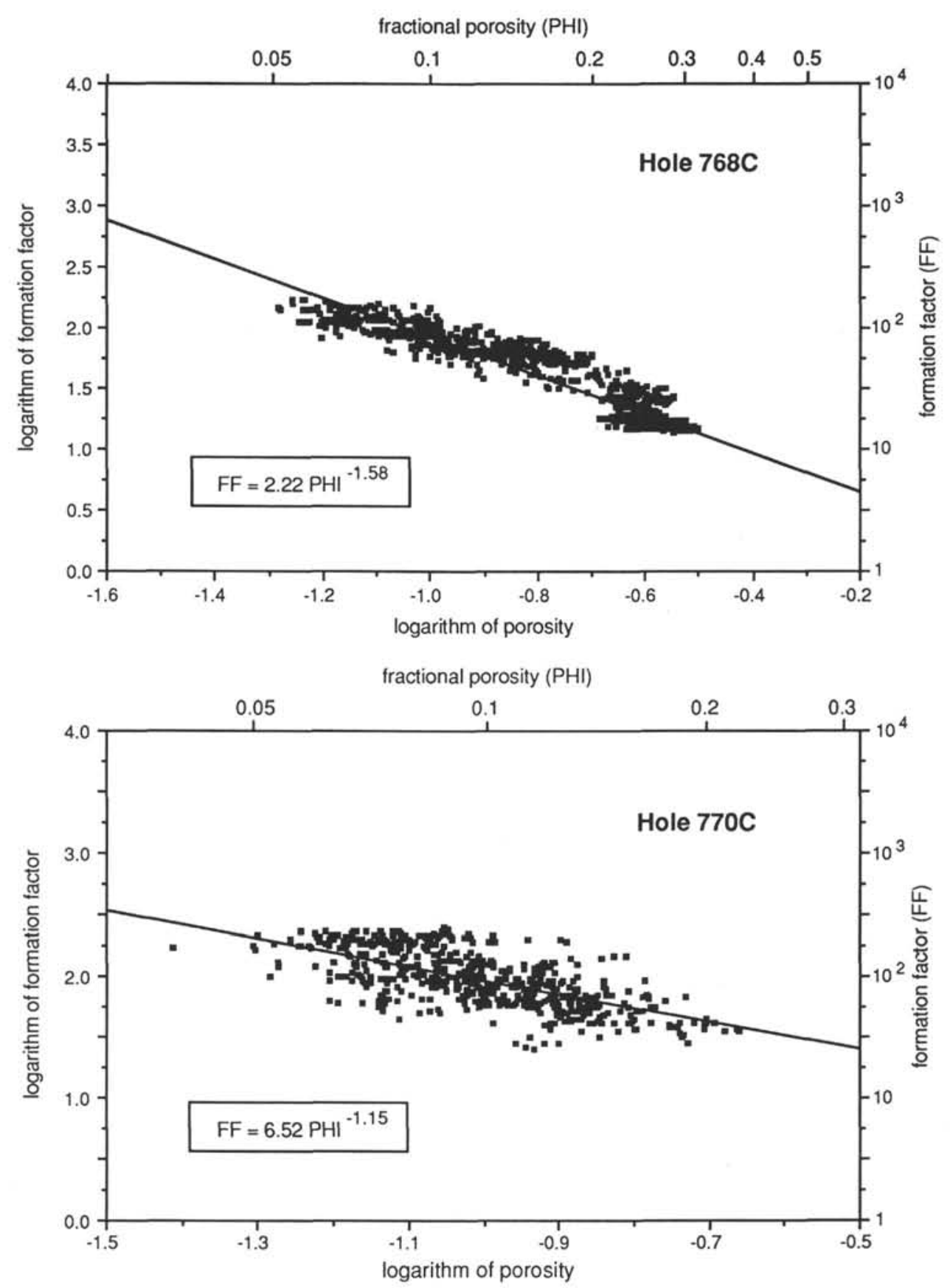

Figure 11. Relationship of formation factor to porosity at Sites 768 (top) and 770 (bottom).

cores at Hole 504B that $F F=10 \varphi^{-1}$. Our estimates from logs at Sites 768 and 770 , as well as those by Jarrard and Schaar (this volume) from cores at the same sites, are significantly different from most previous results. In particular, our estimate of only 2.2-6.5 for $a$ is much lower than the values of $10-30$ obtained elsewhere. Our estimates of 1.2-1.6 for $m$ are within the range of values obtained elsewhere; they indicate a predominance of crack porosity.

\section{Density}

Density logging at Sites 768 and 770 utilized the Schlumberger lithodensity tool. This pad-type tool requires a good contact with the borehole wall for reliable performance. To provide this con- tinuous borehole contact, bowsprings are placed on both sides of the source/detector portion, while two detectors are used for both improved measurement precision and to partially compensate for minor loss of pad contact. At Site 768 the tool apparently functioned well. At Site 770, however, one receiver malfunctioned, forcing us to use a density log that is uncompensated (Shipboard Scientific Party, 1990c). Such uncompensated density logs are very sensitive to washouts, which are enlarged portions of the hole that cause unreliably low-density readings; even compensated density logs occasionally have washout effects. Leg 124 , the last ODP leg before introduction of the more reliable high-temperature lithodensity tool (Schlumberger HLDT), had no caliper for detection of washouts. Consequently, density logs from Sites 768 
and particularly Site 770 must be considered to have a high potential for displaying locally unreliable low values.

Formation bulk density $\left(\rho_{b}\right)$ depends on fractional porosity $(\phi)$, matrix (or grain) density $\left(\rho_{m a}\right)$, and fluid density $\mathrm{rf}$, according to the relation

$$
\rho_{b}=\rho_{m a} \cdot(1-\varphi)+\rho_{f} \cdot \varphi
$$

Fractional porosity is much more variable than matrix density and fluid density within the basalts at any one site. Thus the density $\log$ is a relatively straightforward porosity log, and both $\rho_{m a}$ and $\rho_{f}$ often can be assumed to be constant. Crossplots of matrix density vs. porosity (Fig. 12) for the core analyses of Jarrard and Schaar (this volume) indicate that matrix density does decrease with increasing porosity; this decrease is caused by the greater permeability and therefore increased likelihood of alteration in high-porosity rocks. We utilized equation (6), porosity logs determined from velocity, and the average $\rho_{m a}$ (Jarrard and Schaar, this volume) for each basalt unit, to calculate pseudo-density logs for the basalts of Sites 768 and 770 . Figures 7 and 8 compare these pseudo-density logs to the measurements of core bulk density by Jarrard and Schaar (this volume).

We also created pseudo-density logs directly from transit time, based on regression of bulk density on transit time, again using the measurements of Schaar and Jarrard (this volume). At Site 768 (Fig. 13), this relation was well determined $(R=0.90)$, yielding $\rho_{b}=3.36-0.0115 \cdot \Delta t$, where transit time $(\Delta t)$ is in $\mu \mathrm{s} / \mathrm{ft}$ and density is in $\mathrm{g} / \mathrm{cm}^{3}$. At Site 770 the relation was less reliably determined (Fig. 13), probably due to the smaller porosity range, and was strongly dependent on whether or not we included three breccia samples. We found that $\rho_{b}=3.83-0.0187 \cdot \Delta t$, with $R=$ 0.71 , for regression including the breccia samples. We used these regressions to create pseudo-density logs in Figures 7 and 8.

At Site 768, the two types of pseudo-density logs are remarkably similar in both character and magnitude (Fig. 7); differences between the two of as much as $0.1 \mathrm{~g} / \mathrm{cm}^{3}$ are rare. Further, both are quite similar to discrete core analyses. In contrast, the original density $\log$ (Fig. 4) is consistent with the core analyses and with the pseudo-density logs only within the pillow basalts. Because hole size and rugosity are usually more variable in basalts than in sills, one would normally expect more reliable density logs and therefore better match of log to core in the sills than in the pillows, just the opposite of the observed relation. Although the original density log does capture the basic character of the sills and detects

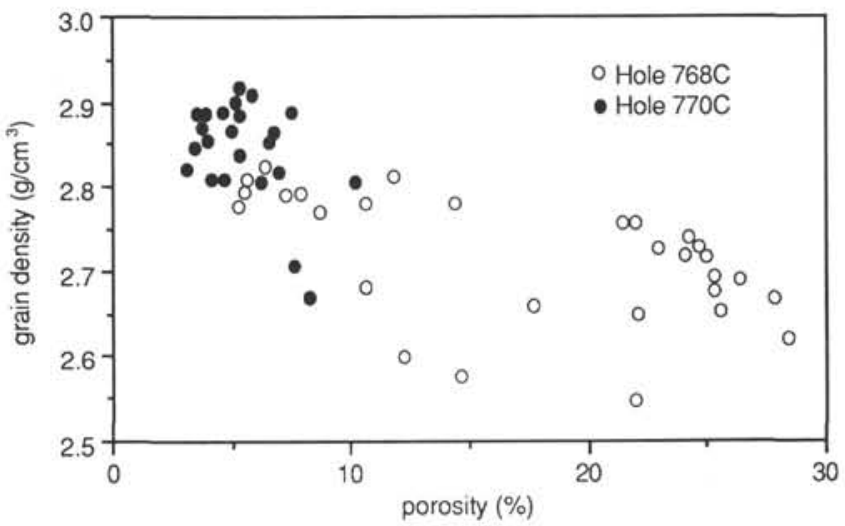

Figure 12. Relationship of matrix density to porosity for discrete core measurements at Sites 768 and 770 (Jarrard and Schaar, this volume). Note the modest tendency for more porous samples to have lower matrix density due to greater alteration. Zoned matrix density values have been used in calculating pseudo-density logs of Figures 7 and 8. the fact that the sills are substantially higher in bulk density than the pillows, it underestimates the sill bulk density by a modest $0.1-0.2 \mathrm{~g} / \mathrm{cm}^{3}$, based on a comparison to both pseudo-density log and discrete core analyses. In general, we conclude that the bulk density $\log$ from Site 768 is of good quality, and that the pseudodensity logs are of very good quality.

Unlike those from Site 768, the two pseudo-density logs from Site 770 are similar in average value but very different in amplitude (Fig. 8). Pseudo-density from sonic porosity predicts a very small range of bulk densities compared to the pseudo-density from a regression including breccia samples; the pseudo-density log from regression excluding breccia samples (not shown) is intermediate in character. Both pseudo-density logs are generally consistent with the core analyses of Jarrard and Schaar (this volume). However, local heterogeneity is so great and large-scale density changes are so subtle that this comparison to core cannot reliably indicate which of the two very different pseudo-density $\log$ s is more accurate. The original uncompensated density $\log$ for Site 770 basalts is similar in density range to the pseudo-density from velocity regression. However, it is consistently about 0.2 $\mathrm{g} / \mathrm{cm}^{3}$ lower than the core measurements and is therefore considered to be less accurate than the pseudo-density logs. We conclude that the pseudo-density log based on velocity regression is generally of good quality, while the original density log is only of fair quality.
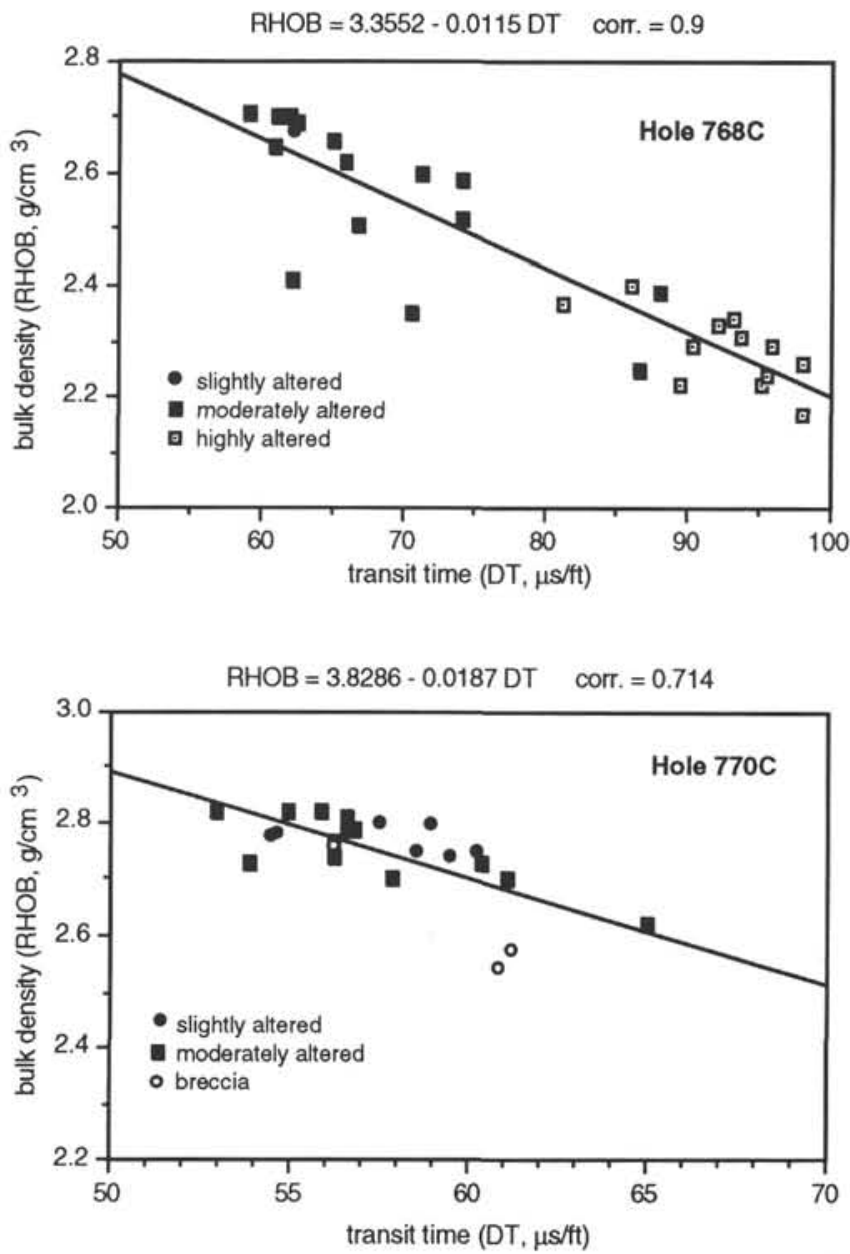

Figure 13. Relationship of transit time to density at Sites 768 (top) and 770 (bottom). 


\section{Neutron Porosity}

ODP neutron-porosity logs are the least reliable of the four log types considered in this study. Several recent studies of DSDP and ODP neutron-porosity logs (Anderson et al., 1985; Broglia and Moos, 1988; Lysne, 1989; Moos, 1990) have found that these logs consistently overestimated the porosity of basalts. Broglia and Ellis (1990) utilized logs from five sites to analyze the relative contributions of several factors to this systematic bias. They concluded that the most important factor is the ODP technique of running the neutron-porosity tool without appropriate eccentralization. At the one site (Site 735) that was logged with a bowspring-eccentralized neutron tool, this bias was absent. Although neutron tools are "compensated" in the sense of applying some correction for tool standoff from the borehole wall, Broglia and Ellis (1990) found that this compensation is insufficient for correction of neutron logs that lack eccentralization.

The neutron logs obtained for the basalts at Sites 768 and 770 were not run eccentralized, because time constraints required that we log the sediments and basalts in the same logging run, and the sediments were so sticky that additional bowsprings would have increased the already very large risk of tool loss. For the same reason, no caliper was run. Thus we expect the neutron logs to give unreliably large porosities due to standoff, yet we have no standoff estimates to permit correction of the neutron logs. For these reasons, we examine neutron log accuracy briefly in the following paragraph but we do not use the neutron logs for interpretation of crustal porosities.

At Site 768 (Fig. 4), neutron porosities are about $40 \%$ in the pillows and $15 \%-35 \%$ in the more massive sills. In both types of formation, comparison to cores (Fig. 4) indicates that porosities are consistently overestimated by $10 \%-20 \%$. At Site 770 , neutron porosities are $20 \%-30 \%$, though core analyses indicate that actual porosities are generally $2 \%-8 \%$ (Fig. 5 ). Though core porosities can be nonrepresentative in basalts due to unmeasured large-scale fracture or pillow porosity, we have already seen that sonic porosities were generally consistent with the core porosities (Figs. 7 and 8). Thus we conclude that the neutron logs at Sites 768 and 770 overestimate porosity by about $10 \%-20 \%$. This discrepancy is near the upper limit of the range of biases detected by Broglia and Ellis (1990) in other ODP crustal sites.

\section{CRUSTAL STRUCTURE}

Our analysis of the geophysical logs from Sites 768 and 770, including comparisons of these logs to discrete core samples, confirmed the reliability of the velocity logs. We found that porosity logs were most accurately determined from velocity, though similar results could have been obtained from resistivity. Pseudo-density from sonic porosity was generally more reliable than raw density logs. In this section, we compare the velocities, densities, and porosities that we have obtained to those determined at other sites, as well as to models of crustal evolution.

Carlson and Herrick (1990) provide an excellent and comprehensive synthesis of the variations of oceanic crustal velocity, density, and porosity with depth and age. Layer $2 \mathrm{a}$ has a velocity of $3.7 \pm 0.4 \mathrm{~km} / \mathrm{s}$, density of less than $2.3 \mathrm{~g} / \mathrm{cm}^{3}$, and porosity of about $30 \%$. Layer $2 \mathrm{~b}$ has a velocity of $5.2 \mathrm{~km} / \mathrm{s}$, density of $2.62-2.69 \mathrm{~g} / \mathrm{cm}^{3}$, and porosity of $10 \%$. These averages by Carlson and Herrick (1990) are based primarily on geophysical logs from Holes 395A (6 Ma), 504B (6 Ma), and 418A (110 Ma). Although many discrete measurements are available from ophiolites (e.g., Salisbury and Christensen, 1978; Christensen, 1978) and both DSDP and ODP basalt cores of a wide range of ages, all such measurements present the problem of representative sampling discussed previously.
The three holes provide a partial picture of the change in oceanic crustal properties with age. However, sonobuoys indicate that layer $2 \mathrm{a}$, with an average thickness of about $1.5 \mathrm{~km}$ for crust $<5 \mathrm{Ma}$, thins gradually with increasing age and may be absent from crust $>40 \mathrm{Ma}$ (Houtz and Ewing, 1976). Layer 2a is approximately $250 \mathrm{~m}$ thick at Hole 395A, 100-175 m thick at Hole 504B, and absent at Hole 418A. Also, recent logging at Site 765 (Shipboard Scientific Party, 1990a), 125-130 Ma, finds no layer 2a. Logging results at all four sites have shown that the layer models of sonobuoys are conceptual oversimplifications; gradual transitions from layer $2 \mathrm{a}$ to layer $2 \mathrm{~b}$ properties are observed. Further, neither these logs nor the standard model for crustal evolution indicates a simple thinning of layer $2 \mathrm{a}$ with time. Instead, porosity throughout layer $2 \mathrm{a}$ is thought to decrease simultaneously due to precipitation of clays, with associated increases in velocity and density (e.g., Broglia and Moos, 1988).

The standard model, in conjunction with syntheses such as that of Carlson and Herrick (1990), makes predictions concerning the velocity, density, and porosity of the upper crust at Sites 768 and 770 . For Site 768 , about $18 \mathrm{Ma}$, we expect an average velocity of about $3.8 \mathrm{~km} / \mathrm{s}$, density of $2.2 \mathrm{~g} / \mathrm{cm}^{3}$, and porosity of $25 \%-30 \%$ for the upper kilometer of crust. For Site 770, about $42 \mathrm{Ma}$, we expect upper crustal properties more like layer $2 \mathrm{~b}$ than like layer 2a: an average velocity of about $5.0 \mathrm{~km} / \mathrm{s}$, density of $2.7 \mathrm{~g} / \mathrm{cm}^{3}$, and porosity of $10 \%-15 \%$ (Carlson and Herrick, 1990). However, seismic models (Kennett and Orcutt, 1976; Purdy, 1983; Vera and Mutter, 1988) show large velocity gradients in the top $2 \mathrm{~km}$ of oceanic crust, so these predicted averages are probably too high for velocity and density and too low for porosity in the top 100-200 m of crust.

At Site 768, observed velocities are predominantly $3-4.5 \mathrm{~km} / \mathrm{s}$, densities are $2.2-2.7 \mathrm{~g} / \mathrm{cm}^{3}$, and porosities are $5 \%-25 \%$ (Fig. 7); the huge difference of properties between pillows and sills, coupled with a $222-\mathrm{m}$ penetration that is large by DSDP or ODP standards but quite thin by seismic standards, makes it misleading to calculate a single average for any of these properties. Predicted velocities for this crustal age are consistent with observations at Site 768 ; they are midway between pillow and sill velocities. In contrast, predicted porosities and densities are very close to observed values for pillow basalts at Site 768 , but substantially different from observed values in the sills.

At Site 770 , observed velocities are predominantly $4.0-5.5$ $\mathrm{km} / \mathrm{s}$, densities are $2.6-2.8 \mathrm{~g} / \mathrm{cm}^{3}$, and porosities are $5 \%-15 \%$ (Fig. 8). These observations coincide well with the predictions, although the crustal penetration of only $106 \mathrm{~m}$ raises serious doubts about how representative such a limited interval is of the upper kilometer of crust.

Given that the predicted velocities, densities, and porosities at the two sites are based on a combination of large-scale seismic models and interpolation between 6- and 110-Ma datums, the agreement between prediction and observation is remarkably good. Unfortunately, we cannot take this as further confirmation of the already generally-accepted standard model. The increase in velocity and density and decrease in porosity at 42 -Ma Site 770 , compared to 18 -Ma Site 768 , is not due to greater alteration-related crack and pore sealing at Site 770. Indeed, we saw in Figures 9 and 10 that all of our crustal-alteration indicators showed that Site 770 is significantly less altered than Site 768 . Nor can we account for this discrepancy by appealing to the back-arc spreading origin of Site 768, as none of our preceding analyses indicated any anomalous behavior of crust at Site 768 . We infer that Site 770 has more "evolved" (faster, more dense, less porous) physical properties not because of greater age and alteration, but because of differences in initial crustal properties. The standard model for crustal aging is probably appropriate at the scale of seismic 
studies and may be appropriate at the scale of deep-penetration sites such as 504B or 418A. Crustal heterogeneity, however, is too high for the standard model to provide useful predictions for crustal samples of 100-200 m at individual sites. Indeed, we have yet to establish how large a sample of oceanic crust is needed for a "representative" sample.

\section{ACKNOWLEDGMENTS}

This project was made possible by the U.S. Science Advisory Committee, grant TAMRF P.O. 20326.

The U.S. science program associated with the Ocean Drilling Program is sponsored by the National Science Foundation and the Joint Oceanographic Institutions, Inc.

\section{REFERENCES}

Anderson, R. N., O'Malley, H., and Newmark, R. L., 1985. Use of geophysical logs for quantitative determination of fracturing, alteration, and lithostratigraphy in the upper oceanic crust, DSDP Holes 504B and 556. In Anderson, R. N., Honnorez, J., et al., Init. Repts. DSDP, 83: Washington (U.S. Govt. Printing Office), 443-478.

Archie, G. E., 1942. The electrical resistivity log as an aid in determining some reservoir characteristics. J. Pet. Tech., 5:1-8.

Broglia, C., and Ellis, D., 1990. Effect of alteration, formation absorption, and standoff on the response of the thermal neutron porosity log in gabbros and basalts: examples from Deep Sea Drilling Project-Ocean Drilling Program sites. J. Geophys. Res., 95:9171-9188.

Broglia, C., and Moos, D., 1988. In-situ structure and properties of 110-Ma crust from geophysical logs in DSDP Hole 418A. In Salisbury, M. H., Scott, J. H., et al., Proc. ODP, Sci. Results, 102: College Station, TX (Ocean Drilling Program), 29-47.

Carlson, R. L., and Herrick, C. N., 1990. Densities and porosities in the oceanic crust and their variations with depth and age.J. Geophys. Res., 95:9153-9170.

Christensen, N. I., 1978. Ophiolites, seismic velocities and oceanic crustal structure. Tectonophysics, 47:131-157.

Christensen, N. I., Blair, S. C., Wilkens, R. H., and Salisbury, M. H., 1980. Compressional wave velocities, densities and porosities of basalts from Holes 417A, 417D and 418A. In Donnelly, T., Francheteau, J., Bryan, W., Robinson, P., Flower, M., Salisbury, M., et al., Init. Repts. DSDP , 51, 52, 53 (Pt. 2): Washington (U.S. Govt. Printing Office), 1467-1471.

Gassmann, F., 1951. Elastic waves through a packing of spheres. Geophysics, 16:673-685.

Hamilton, E. L., 1976. Variations in density and porosity with depth in deep-sea sediments. J. Sediment. Petrol., 46:280-300.

Houtz, R., and Ewing, J., 1976. Upper crustal structure as a function of plate age. J. Geophys. Res., 81:2490-2498.

Hyndman, R. D., Christensen, N. I., and Drury, M. J., 1984. The physical properties of basalt core samples from Deep Sea Drilling Project Leg 78B, Hole 395A. In Hyndman, R. D., Salisbury, M. H., et al., Init. Repts. DSDP, 78B: Washington (U.S. Govt. Printing Office), 801810 .

Kennett, B.L.N., and Orcutt, J. A., 1976. A comparison of travel time inversions for marine refraction profiles. J. Geophys, Res., 81:40614070.
Kuster, G. T., and Toksöz, M. N., 1974. Velocity and attenuation of seismic waves in two-phase media: Part I - theoretical formulation. Part II - experimental results. Geophysics, 39:587-607.

Lysne, P., 1989. Investigation of neutron-porosity log uncertainties: Ocean Drilling Program Hole 642E. In Eldholm, O., Thiede, J., Taylor, E., et al., Proc. ODP, Sci. Results, 104: College Station, TX (Ocean Drilling Program), 973-977.

Moos, D., 1990. Petrophysical results from logging in DSDP Hole 395A, ODP Leg 109. In Detrick, R., Honnorez, J., Bryan, W. B., Juteau, T., et al. Proc. ODP, Sci. Results, 106/109: College Station, TX (Ocean Drilling Program), 237-253.

Olhoeft, G. R., 1981. Electrical properties of rocks. In Touloukian, Y. S., Judd, W. R., and Roy, R. F. (Eds.), Physical Properties of Rocks and Minerals: New York (McGraw-Hill), 257-330.

Pape, H., Riepe, L., and Schopper, J. R., 1982. Petrophysical detection of microfissures in granites. SPWLA 26th Ann. Log Symp., Dallas, TX, Paper P.

Pezard, P. A., 1990. Electrical properties of mid-ocean ridge basalt and implications for the structure of the upper oceanic crust in Hole 504B. J. Geophys. Res., 95:9237-9264.

Purdy, G. M., 1983. The seismic structure of 140 Myr old crust in the western central Atlantic Ocean. Geophys. J. R. Astron. Soc., 72:115137.

Salisbury, M. H., and Christensen, N. I., 1978. The seismic velocity structure of a traverse through the Bay of Islands ophiolite complex, Newfoundland: an exposure of oceanic crust and upper mantle. $J$. Geophys. Res., 83:805-817.

Serra, O., 1984. Fundamentals of Well Log Interpretation: The Acquisition of Logging Data: Amsterdam (Elsevier). 1986. Fundamentals of Well Log Interpretation: The Interpretation of Logging Data: Amsterdam (Elsevier).

Shipboard Scientific Party, 1987. Site 645. In Srivastava, S. P., Arthur, M., et al., Proc. ODP, Init. Repts., 105: College Station, TX (Ocean Drilling Program), 61-418.

1990a. Site 765. In Gradstein, F. M., Ludden, J. N., et al., Proc. $O D P$, Init. Repts., 123: College Station, TX (Ocean Drilling Program), 63-267.

1990b. Site 768. In Rangin, C., Silver, E. A., von Breymann, M. T., et al., Proc. ODP, Init. Repts., 124: College Station, TX (Ocean Drilling Program), 195-297.

1990c. Site 770. In Rangin, C., Silver, E. A., von Breymann, M. T., et al., Proc. ODP, Init.Repts., 124: College Station, TX (Ocean Drilling Program), 343-397.

Toksöz, M. N., Cheng, C. H., and Timur, A., 1976. Velocities of seismic waves in porous rocks. Geophysics, 41:621-645.

Vera, E. E., and Mutter, J. G., 1988. Crustal structure in the Rose area of the East Pacific Rise: one-dimensional travel time inversion of sonobuoys and expanded spread profiles. J. Geophys. Res., 93:6635-6648.

Waxman, H. H., and Smits, L.J.M., 1968. Electrical conductivities in oil-bearing shaly sands. Trans. AIME, 243.

Winsauer, W. O., and McCardell, W. M., 1953. Ionic double-layer conductivity in reservoir rocks. Petrol. Trans. AIME, 198:129-134.

Wyllie, M.R.J., Gregory, A. R., and Gardner, L. W., 1956. Elastic wave velocities in heterogeneous and porous media. Geophysics, 21:41-70.

Date of initial receipt: 6 July 1990

Date of acceptance: 8 January 1991

Ms 124B-125 